\title{
The Effect of Functional-Analytic Teaching on Aspects of French Immersion Students' Sociolinguistic Competence
}

\author{
ROY LYSTER
}

McGill University

This study investigated the effect of functional-analytic teaching on aspects of French immersion (FI) students' sociolinguistic competence at the Grade 8 level. A set of functional-analytic materials, entailing the study and practice of sociostylistic variation, was implemented in three FI classrooms by their respective teachers during French language arts classes over an average period of five weeks. A pre-test, an immediate post-test, and a delayed post-test were administered to the experimental group as well as to a comparison group in order to compare classes on three measures of sociolinguistic competence (defined as the ability to recognize and produce socially appropriate language in context). The study demonstrated that functional-analytic teaching substantially improved aspects of FI students' sociolinguistic competence in at least three ways: (1) by significantly increasing their ability in oral production to appropriately and accurately use vous in formal situations; (2) by significantly increasing their ability in written production to appropriately use vous in formal letters, and, in the short run, to use polite closings in formal letters; and (3) by significantly increasing their ability to recognize contextually appropriate French.

\section{BACKGROUND}

This study follows a series of experiments investigating the effects of instruction on second language (L2) learning in communicatively oriented classrooms. It derives support from L2 curriculum theorists who advocate the inclusion of an analytic focus in communicative language teaching (e.g. Allen 1983; Finocchiaro and Brumfit 1983; Brumfit 1984; Rutherford 1987; Yalden 1987; Stern 1990,1992 ), and from researchers concerned with classroom-based investigations into the effects of form-focused instruction on L2 learning in communicative contexts (e.g. Harley 1989; Lightbown and Spada 1990; Day and Shapson 1991; Long 1991; White 1991; Sharwood Smith 1993; Spada and Lightbown 1993). The study aims to counter the limited role attributed to the effectiveness of analytic teaching in Krashen's Monitor Model (Krashen 1982, 1985), and to lend empirical support to the information-processing model of L2 learning (e.g. McLaughlin 1987, 1990; O'Malley, Chamot, and Walker 1987; Hulstijn 1990) whereby automaticity in L2 performance may be developed via practice at the level of controlled processing. 
The present study draws on the analytic-experiential dimension in $\mathrm{L} 2$ teaching as characterized by Stern $(1990,1992)$. Analytic teaching strategies are those which emphasize accuracy and focus on aspects of the L2 (including phonology, grammar, functions, discourse, and sociolinguistics), and which entail the study and practice of language items and rehearsal of L2 skills. Experiential teaching strategies, according to Stern, include authentic themes and topics as content, aim to engage students in 'purposeful activity', and emphasize the conveyance of meaning, fluency over accuracy, and language use as 'real talk'. Stern stresses the need to consider the analytic-experiential option on a continuum rather than as a dichotomy. He advocates the integration of analytic and experiential strategies in variable proportions in response to learners' needs and program objectives, and advises against the use of only one type of strategy in L2 classrooms. For example, on the one hand, he suggests that regular French L2 programs, involving French language study in what usually amounts to one class per school day, should begin to emphasize more experiential strategies to counter their prevalent focus on language analysis. On the other hand, he suggests that French immersion (FI) programs, in which students are taught a major portion of their content subjects in French, need to 'add ways of combining experiential teaching with some degree of necessary and helpful analytic support' (1990: 108). ${ }^{1}$

The tension between analytic and experiential strategies in language teaching is not new. The extent to which and the ways in which such strategies may be combined in order to facilitate L2 learning in classroom settings, as well as why this is so, continue to constitute major issues in L2 pedagogy. Immersion programs contribute to the debate in interesting ways, in that they are considered to be exemplary contexts of communicative language teaching due to their emphasis on L2 learning through the study of other school subjects taught in the L2. Immersion students typically receive a great deal of comprehensible input in their L2 through subjects such as mathematics, science, history, and geography, and they perform as well as their counterparts in the regular English program on achievement tests in these subjects (Lambert and Tucker 1972; Swain and Lapkin 1982; Genesee 1987). Yet the linguistic performance of these same students continues to be clearly non-native-like, in spite of extensive comprehensible input, particularly with respect to grammatical and sociolinguistic competencies, as indicated by research findings such as those in Harley, Cummins, Swain, and Allen (1990). These investigators (Allen, Swain, Harley, and Cummins 1990) suggest that effective ways of improving the French proficiency of FI students may include analytic teaching strategies.

Analytic language teaching, however, is not new in FI programs and has indeed been observed in classrooms where the French language continues to receive explicit attention through French language arts classes which constitute a substantial portion of the program. Yet the analytic teaching which has been observed (Swain and Carroll 1987) tends to limit itself to decontextualized grammar teaching emphasizing the learning and categorizing of forms rather than relating the forms to meaning in context. 
In order to diffuse this dichotomous view of language teaching where language analysis is pursued in isolation relative to the broader communicative context, immersion pedagogy needs to be reconceptualized in ways which take more account of possibilities for effectively integrating analytic teaching into the predominantly experiential context of immersion, and furthermore, which go beyond the standard definition of immersion generally expressed in terms of program design, namely, the study of other subjects in the L2. Swain (1988a) illustrates with examples from immersion classrooms that content teaching alone is not a priori good language teaching. She stresses the need for immersion pedagogy to allow for contrived input which would make certain functional or structural features more salient. Harley and Swain (1984) propose that selective grammatical explanation be integrated into the immersion context in order to expose students to forms otherwise redundant and/or infrequent in classroom discourse. They hypothesize (ibid.: 310 ) that there is a twofold need in immersion:

1. for the provision of more focussed L 2 input which provides the learners with ample opportunity to observe the formal and semantic contrasts involved in the relevant target subsystem (this does not necessarily involve explicit grammar teaching); and

2. for the increased opportunity for students to be involved in activities requiring the productive use of such forms in meaningful situations.

In terms of L2 curriculum theory, such mediation between structural and experiential approaches may be realized through Allen's (1983) three-level curriculum model, which variably emphasizes structural-analytic, functionalanalytic, and non-analytic components. The functional-analytic component focuses on discourse features of language and involves equal reference to language as a medium and language as communication. Such an approach is concerned with 'the way the learner's formal linguistic knowledge is made use of in accomplishing a variety of communicative tasks' (Allen 1983: 37).

Two experimental studies (Harley 1989; Day and Shapson 1991) have been undertaken in immersion classrooms in an attempt to demonstrate that language instruction in these communicative contexts can be presented in ways which highlight and encourage the use of difficult L 2 features in meaningful contexts, and concomitantly, that such instruction can improve the learners' L2 proficiency. Both studies drew on Allen's curriculum model, emphasizing the integration of the functional-analytic component into the experiential (nonanalytic) context provided by FI classrooms. Both studies used a pre-test-posttest design to compare results of an experimental group (six classes exposed to treatment materials) to that of a comparison group (six classes not exposed to the materials) on three measures: a cloze test, a composition task, and an oral interview.

Harley's (1989) study was undertaken in Grade 6 FI classrooms to determine the effect of a set of curriculum materials highlighting functional distinctions between the imparfait and the passé composé in French. The materials were implemented for approximately twelve hours during an eight-week period. 
Immediate post-test results revealed benefits on the cloze test and the oral interview for the experimental group, but no statistically significant differences between the experimental and comparison groups on the composition task. Three months later, on the delayed post-test, no significant differences were found between groups on any of the measures.

Day and Shapson (1991) continued Harley's line of investigation through an experimental study undertaken in FI classrooms at the Grade 7 level. The linguistic focus of the materials, implemented for an average of 17.4 hours during a six-week period, was the use in French of the conditional mood to express a hypothetical situation and as a politeness marker. The communicative context entailed the planning of an imaginary space colony. On the immediate post-test, the experimental group made significant gains on the cloze test and the written composition, but not on the oral interview. The experimental group maintained these gains and continued to significantly outperform learners in the comparison group on the cloze test and the written composition at the time of the delayed post-test eleven weeks later.

The present study follows the design of the Harley (1989) and Day and Shapson (1991) studies and builds on them in at least two ways. First, this study is undertaken at a higher grade level. The Grade 8 students involved in the present study are presumed to be more cognitively mature than Grade 6 and 7 students, and accordingly, are presumed to be more predisposed to language analysis. Consequently, the focus in the present study is generally more analytic than that of the other studies. Second, the previous two studies focused on verbs, aiming to improve aspects of FI students' grammatical competence. Aiming to improve aspects of sociolinguistic competence, the present study illustrates that analytic language teaching need not be restricted to grammar teaching; it also includes the study and practice of language functions and sociolinguistic features.

Sociolinguistic competence in this study is characterized as the ability to recognize and produce contextually appropriate language, including sensitivity to differences in variety and register. Studies have indicated that immersion students generally learn one classroom register and have difficulty in varying their use of French in accordance with social context (Swain and Carroll 1987; Harley, Cummins, Swain, and Allen 1990; Swain and Lapkin 1990). For example, after ten years in an immersion program, students use significantly fewer conditionals as politeness markers than do native speakers, and continue to use $t u$ almost exclusively in formal contexts rather than the more native-like use of vous. Accordingly, the present study includes a specific focus on the use of $t u$ and vous as markers of contextually appropriate language.

Sociolinguistic competence is but one trait in the model of communicative competence posited by Canale and Swain (1980) and Canale (1983) who suggest that communicative language teaching must address itself minimally to the development of grammatical, sociolinguistic, discourse, and strategic competencies. Since one of the goals of FI programs is to facilitate communication between anglophone and francophone Canadians, an emphasis on the develop- 
ment of sociolinguistic competence is justified insofar as sociolinguistically appropriate ways of using French, including appropriate uses of $t u$ and vous, provide keys to successful entry into authentic interaction with native speakers.

\section{DESIGN OF THE EXPERIMENT}

Treatment materials which were developed specifically for the experiment were implemented by three teachers in their Grade 8 FI classes (referred to as Classes 1,2 , and 3) for an average of twelve hours during French language arts over an average period of five weeks. Prior to the treatment, pre-tests were administered to the three experimental classes and to two comparison classes (two Grade 8 FI classes not receiving the treatment, referred to as Classes 4 and 5). Throughout the treatment, experimental and comparison classes were observed and experimental students and teachers completed questionnaires evaluating the curriculum unit. After the treatment in experimental classes, immediate post-tests, followed by delayed post-tests one month later, were administered to all five classes. A repeated measures analysis of variance was then conducted on test results in order to compare the relative growth of all five classes on three measures of sociolinguistic competence.

\subsection{Sample}

The sample consisted of 106 Grade 8 FI students in five classes from three different schools in two school boards in suburban areas of Metropolitan Toronto. All students' first language (L1) was English, and all were enrolled in early immersion programs, meaning that upon entry into the program at the age of five, instruction was wholly in French. English was introduced by Grade 2, and then instruction in English was progressively increased, so that by Grade 8, these students' instructional day was fifty per cent in English and fifty per cent in French.

Class 1 was taught by a male in his second year of teaching, referred to as Teacher 1, who considers English to be his L1 although he speaks French 8090 per cent of the time with francophone parents. Class 3 was taught by a francophone male, referred to as Teacher 3, in his eighth year of teaching, including three years in FI at his current school. Class 5 was taught by a francophone male, referred to as Teacher 5 , in his third year of teaching but his first year at his current school. Both Class 2 (experimental) and Class 4 (comparison) were taught by the same male francophone who had taught for twentytwo years, including eight years in FI. He is referred to as Teacher $2 .^{2}$

\subsection{Procedures}

The first part of the study entailed the development of the treatment materials which were piloted in a Grade 8 classroom and a Grade 9 classroom and revised accordingly. The next step involved the development and piloting of testing materials. A set of sociolinguistic tests, which had been developed by researchers at the Ontario Institute for Studies in Education as part of the Development of Bilingual Proficiency Project (Harley, Cummins, Swain, and 
Allen 1990), was made available for adaptation in the present study. The tests included an oral production (OP) test, a written production (WP) test, and a multiple-choice $(\mathrm{MC})$ test. The adapted versions were piloted in a Grade $8 \mathrm{FI}$ class, modified accordingly, and then piloted again in another Grade 8 FI class.

Prior to the treatment, pre-tests were administered to all five participating classes. The OP test was administered to a randomly selected subsample of twelve students withdrawn individually from each class. There were two forms of the OP test. Half the subsample was given Form A while the other half was given Form B. The WP and MC tests were administered to all students in each class. The WP test also had two forms so that half the class received Form $A$ and the other half received Form B. Upon completion of the pre-testing, a day-long workshop was held for the three experimental teachers in order to explain and discuss the treatment materials in conjunction with the teachers' guide which specified the timing for all activities on a day-to-day basis.

All five classes were observed during the treatment in an attempt to account for potential differences among classes. Observations were undertaken in the three experimental classrooms in order to document the procedures utilized by each teacher to implement the treatment materials. Observations were undertaken in comparison classes, to a much lesser degree, in order to ascertain whether socio-stylistic variation received any explicit, or perhaps implicit, attention in the content of French language arts classes.

Following the teaching of the treatment materials, immediate post-tests were administered to all five classes. All students took the same MC test again, while test forms for the WP test were reversed so that students who had written Form A for the pre-test wrote Form $B$ for the immediate post-test, and vice versa. The OP test was readministered to the same subsample in each class, again reversing the forms of the test. One month later, delayed post-tests were administered to all classes. All students received the same MC test and the same form of the WP test they had completed at the time of pre-testing. Similarly, the subsample of twelve students from each class was administered the same form of the OP test that each student had completed as a pre-test. Finally, all teachers were asked to describe the content of their language arts classes since the administration of immediate post-tests.

\subsection{Description of treatment materials}

The treatment materials consisted of a curriculum unit entitled Variation en situation de communication: unité sur les niveaux de langue en français (Lyster 1994b). Following Stern's (1992) characterization of functional-analytic teaching, the content of the unit highlighted sociolinguistic variation, context, participant roles, and speech acts. First and foremost, the focus was on how language varies according to social context (formal versus informal contexts), and to a lesser degree, on how language varies according to geographic context (Canadian versus European lexical variants). The materials aimed to provide input highlighting distinctions in socio-stylistic variation, and production activities requiring learners to make choices pertaining to the appropriate use of 
such distinctions. Teaching strategies used to implement the unit generated the following types of activities and practice:

1. Explicit techniques, such as observations involving comparisons and contrasts of various speech acts in formal and informal contexts, allowed students to perceive language functions and their appropriate forms in a variety of contexts.

2. Role plays promoted face-to-face interaction and peer correction through opportunities to practise communicative functions within contrived contexts requiring socio-stylistic variation (e.g. asking for and giving directions, proposing an activity, accepting and refusing invitations).

3. Structural exercises highlighted verb inflections resulting from the use of $t u$ or vous.

4. Writing activities required the production of letters and invitations using formal and informal registers.

5. Intensive reading activities focused on the use of $t u$ and vous in dialogues extracted from a novel written for and about teenagers, and on lexical differences between French from France and French from Quebec.

6. Cooperative learning activities allowed students, on the one hand, to discover differences between formal and informal uses of French in a variety of contexts, in addition to differences between oral and written French within these two levels of formality, and on the other, to apply these stylistic differences in projects undertaken in groups, necessitating extensive negotiation in the L2 among students.

\subsection{Description of tests and scoring procedures}

Given the variable nature of the use of socio-stylistic features, all measures designed to assess sociolinguistic competence were administered to a group of native speakers in Quebec City between the ages of 13 and 15. The native speakers were students attending a secondary school which had been recommended by the local school board and described as having a similar socioeconomic status to that of the schools in the present study. The WP test and the $\mathrm{MC}$ test were administered to 81 native speakers, and the OP test to a subsample of 44 . The results were designed to represent the sociolinguistic norm of adolescent francophones from Quebec City. This norm provided the basis on which scoring procedures were subsequently established as rating scales ranging from more appropriate to less appropriate, and not as dichotomous scales of either right or wrong. Details concerning the native-speaker data are described in Lyster (1993).

Written production test. The WP test consisted of two tasks-the writing of an informal note and the writing of a formal letter. On Form A, for example, the informal task entails a situation in which students have been remiss in tidying their bedroom and the living room even though company is expected that evening. They are asked to write the note that their mother would likely write to 
them in that situation. In the formal task, a situation is described to students in which they have moved with their family into a new apartment where the landlord does not allow dogs. They are asked to write a letter to the landlord persuading him to allow the dog to stay.

Scoring was based on 'difference' scores, calculated by subtracting the number of formal features produced in the note from those produced in the letter. The difference score was intended to reflect the subjects' ability to vary their written language between formal and informal situations. A high difference score would reflect more variation than a low difference score.

In view of the native-speaker data, the following features were expected to appear in formal letters but not in notes, and were scored accordingly:

1. use of (a) fixed politeness expressions (e.g. s'il vous plait, avec votre permission, si possible), and/or (b) use of direct questions (e.g. Est-ce que je peux garder mon chien?) or indirect questions (e.g. Je voulais vous demander si...);

2. use of the conditional;

3. use of vous;

4. use of polite closings (such as Merci and Merci beaucoup or longer closings such as Merci de votre compréhension and Je vous remercie à l'avance).

The WP tests were scored by the investigator, and another highly proficient speaker of French rescored a randomly selected set consisting of 10 per cent of the tests. There was a .96 level of agreement, indicating high inter-rater reliability.

Oral production test. Students taking the OP test were tested individually. They were shown slides of people in a variety of situations while the investigator described a specific context and asked students to respond as if they were actually addressing the person pictured on the slide. Students were required to perform five different speech acts (such as requesting or giving directions, requesting help in math, or offering to help carry books). Each speech act was produced in both an informal and a formal context. Informal situations consisted of interactions with allegedly known peers, while formal situations depicted either unknown adults, the school librarian, or the math teacher.

Students' tape-recorded responses were transcribed and scored according to a four-point scale which had been designed to reflect native-speaker usage of $t u$ and vous. ${ }^{3}$ The OP tests were scored by the investigator, and a native speaker of French rescored a randomly selected set consisting of 10 per cent of the tests. There was a .95 level of agreement, indicating high inter-rater reliability. Although administered as one test, the OP test was scored and analyzed as two separate tests: a formal oral production test and an informal oral production test. $^{4}$

Multiple choice test. The MC test consisted of 18 items. Of these, 14 items presented a specific context (e.g. between friends at school, between pharmacist 
and customer at the drugstore, in a note from husband to wife, etc.). Each context was followed by 3 possible utterances representing different styles of discourse. Students were to choose the utterance which best suited the given context. In each of 4 other items, an utterance was presented followed by 3 possible contexts in which the utterance may have been produced. Students were to choose the most likely context. Items were scored according to weights assigned to the options based on the native speakers' choices. To assign weights to the options, the following four-point scale was adopted:

3 points if chosenby $80-100$ per cent of the native speakers;

2 points if chosen by 50-79 per cent of the native speakers;

1 point if chosen by $15-49$ per cent of the native speakers;

0 points if chosen by less than 15 per cent of the native speakers.

The maximum possible score on the MC test was 50 points (not all items permitted a maximum score of 3; maximum score for some items was only 2 ). Using immediate post-test scores of $104 \mathrm{FI}$ students, an adequate level of test reliability was obtained (alpha $=.71){ }^{5}$

\section{RESULTS}

In this section, the findings for each measure of sociolinguistic competence are presented. Classroom observations, which allowed for the conclusion that instruction in French language arts periods in the comparison classes did not focus on aspects of socio-stylistic variation, and results of questionnaires completed by experimental students and teachers, are reported and discussed in Lyster (1993).

\subsection{Statistical design and preliminary analyses}

Statistical comparisons of the five classes were undertaken using SPSS-X MANOVA, a program intended to perform multivariate analysis of variance, including analysis of repeated measures. Since there were five classes, comparisons were made using the student as the unit of analysis and four contrasts were made within the design of the repeated measures MANOVA. The following contrasts were chosen in accordance with the design of the experimental study and in line with patterns which emerged in the class means (these patterns will become evident as the results are presented):

Parameter 1: Classes 1, 2, 3 vs. Classes 4, 5 (are the experimental classes different from the comparison classes?);

Parameter 2: Class 4 vs. Class 5 (are the two comparison classes different from one another?);

Parameter 3: Class 3 vs. Classes 1 and 2 (is Class 3 different from the other two experimental classes?);

Parameter 4: Class 1 vs. Class 2 (are the other two experimental classes different from one another?). 
Since the WP test and the OP tests each had two forms, test order was initially considered a between-subjects factor in the analysis of these variables. However, test order was found to have no significant effect and was subsequently dropped from the analysis. Preliminary analyses comparing pre-test scores revealed a significant difference between the experimental group and the comparison on the OP formal test $(F(1,55)=4.54, p<.05)$, with the experimental group performing better. Since the repeated measures analysis evaluates rates of change, no adjustments needed to be made to pre-test scores. ${ }^{6}$

\subsection{Written production results}

The mean WP scores for the five classes obtained on the three occasions are presented in Table 1 and displayed graphically in Figure 1. (Note that the thick horizontal line on this graph and on all subsequent line graphs indicates the mean score obtained by adolescent native speakers on one occasion.) The

Table 1: Class means on WP test

\begin{tabular}{lllllll}
\hline & \multicolumn{2}{c}{ Pre-test } & \multicolumn{2}{c}{ Immediate post-test } & \multicolumn{2}{c}{ Delayed post-test } \\
& mean & $S D$ & mean & $S D$ & mean & $S D$ \\
\hline $\begin{array}{l}\text { Class 1 } \\
(n=27)\end{array}$ & 1.7 & 1.5 & 3.1 & 1.3 & 2.9 & 1.3 \\
$\begin{array}{l}\text { Class 2 } \\
(n=23)\end{array}$ & 1.7 & 1.3 & 3.0 & 1.3 & 3.0 & 1.6 \\
$\begin{array}{l}\text { Class 3 } \\
(n=16)\end{array}$ & 3.1 & 1.2 & 2.9 & 1.3 & 2.9 & 1.5 \\
$\begin{array}{l}\text { Class 4 } \\
(n=21)\end{array}$ & 1.7 & 1.3 & 1.3 & 1.2 & 1.2 & 1.2 \\
$\begin{array}{l}\text { Class 5 } \\
(n=16)\end{array}$ & 2.5 & 1.0 & 1.9 & 1.5 & 1.8 & 1.6 \\
\hline
\end{tabular}

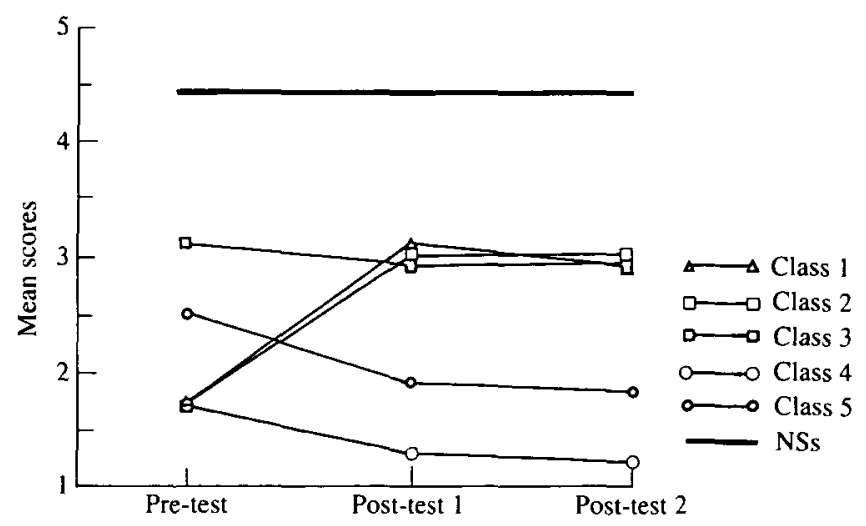

Figure 1: Mean scores on WP test 
univariate analysis, comparing the grand mean of the five classes over the three occasions, revealed a significant overall class effect $(F(4,98)=7.35$, $p<.0001)$. The three experimental classes performed significantly better than the two comparison classes $(F(1,98)=23.27, p<.0001)$, and the two comparison classes were significantly different from each other $(F(1,98)=4.40$, $p<.05$ ). The other two contrasts were not significant.

Multivariate $F$ tests revealed a significant overall time effect $(F$ (2, $97)=4.36, p<.02)$, and a significant overall class-by-time interaction $(F(8$, $194)=4.30, p<.0001)$. The performance of the three experimental classes proved to be significantly different from that of the two comparison classes over time $(F(2,97)=12.30, p<.0001)$. At the same time, Class 3 performed significantly differently from Classes 1 and $2(F(2,97)=6.20, p<.01)$, while the other two contrasts did not reveal significant class-by-time interactions.

Analysis of the WP test was expanded to include an examination of its component scores in order to reveal a more detailed picture of students' performance. The statistical analysis takes account of the experimental and comparison classes only as two distinct groups rather than five distinct classes, and first compares each group's pre-test results to immediate post-test results, and then pre-test results to delayed post-test results. ${ }^{7}$ The means and standard deviations obtained on three occasions by the experimental and comparison groups for each formal language feature are presented in Table 2. Also displayed in this table are the results obtained by the sample of 81 adolescent native speakers. Note that the high standard deviations indicate a considerable amount of variability within groups.

Significant differences emerged primarily in the experimental students' use of vous, both between pre-test and immediate post-test $(Z=4.55, p<.0001)$, and between pre-test and delayed post-test $(Z=4.67, p<.0001)$. To a lesser degree, significant differences emerged in their use of polite closings between pre-test and immediate post-test $(Z=2.12, p<.05)$, but were not maintained at the time of delayed post-testing. No significant differences emerged over time in the experimental group's use of conditionals nor in the use of questions and/ or politeness expressions. Regarding the comparison group, no significant differences emerged over time for any of the four categories analyzed in the WP test.

\subsection{Informal oral production results}

The maximum possible score on the OP informal test was 15 points and the mean score attained by the sample of 44 native speakers was $14.9(S D=.5)$. Mean scores obtained by the five classes on three administrations of the OP informal test are displayed in Table 3 and represented graphically in Figure 2.

With the exception of Class 3 , results on the OP informal test indicated that students had few difficulties using $t u$ in informal situations, leaving little room for improvement over time. Univariate $F$ tests, however, revealed variability amongst classes on the grand mean, and indeed the class effect was significant $(F$ $(4,51)=7.33, p<.0001)$. Class 4 differed significantly from Class $5(F$ 


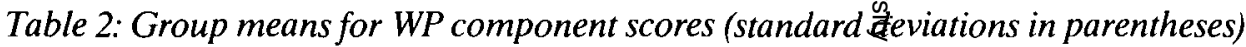

\begin{tabular}{|c|c|c|c|c|c|c|c|c|}
\hline & \multirow[b]{2}{*}{ Native speakers } & \multicolumn{2}{|c|}{ Pre-test } & \multirow{2}{*}{ @. } & \multicolumn{2}{|c|}{ Immediate post-test } & \multicolumn{2}{|c|}{ Delayed post-tes } \\
\hline & & Exp. & comp. & & Exp. & comp. & Exp. & comp. \\
\hline Questions/politeness expressions & $\begin{array}{c}.72 \\
(.51)\end{array}$ & $\begin{array}{c}.76 \\
(.46)\end{array}$ & $\begin{array}{c}.65 \\
(.48)\end{array}$ & 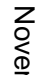 & $\begin{array}{c}.69 \\
(.50)\end{array}$ & $\begin{array}{c}.63 \\
(.63)\end{array}$ & $\begin{array}{c}.71 \\
(.46)\end{array}$ & $\begin{array}{c}.55 \\
(.55)\end{array}$ \\
\hline Conditionals & $\begin{array}{c}.57 \\
(.55)\end{array}$ & $\begin{array}{c}.29 \\
(.49)\end{array}$ & $\begin{array}{l}.22 \\
(.48)\end{array}$ & $\frac{\vec{D}}{\frac{D}{N}}$ & $\begin{array}{r}.27 \\
(.57)\end{array}$ & $\begin{array}{c}.16 \\
(.37)\end{array}$ & $\begin{array}{c}.26 \\
(.54)\end{array}$ & $\begin{array}{c}.18 \\
(.39)\end{array}$ \\
\hline Vous & $\begin{array}{l}1.95 \\
(.27)\end{array}$ & $\begin{array}{c}.49 \\
(.78)\end{array}$ & $\begin{array}{c}.49 \\
(.77)\end{array}$ & $\begin{array}{l}\text { N } \\
\text { No } \\
\end{array}$ & $\begin{array}{l}1.28 \\
(.73)\end{array}$ & $\begin{array}{c}.38 \\
(.76)\end{array}$ & $\begin{array}{l}1.39 \\
(.82)\end{array}$ & $\begin{array}{c}.29 \\
(.77)\end{array}$ \\
\hline Polite closings & $\begin{array}{l}1.20 \\
(.89)\end{array}$ & $\begin{array}{c}.51 \\
(.59)\end{array}$ & $\begin{array}{c}.70 \\
(.74)\end{array}$ & 0 & $\begin{array}{c}.76 \\
(.84)\end{array}$ & $\begin{array}{c}.42 \\
(.64)\end{array}$ & $\begin{array}{c}.61 \\
(.70)\end{array}$ & $\begin{array}{c}.45 \\
(.55)\end{array}$ \\
\hline
\end{tabular}

Note: native speakers $(n=81)$; experimental group $(n=66)$; comparison group $(n=37)$ 
Table 3: Class means on OP informal test

\begin{tabular}{lcclccc}
\hline & \multicolumn{2}{c}{ Pre-test } & \multicolumn{2}{c}{ Immediate post-test } & \multicolumn{2}{c}{ Delayed post-test } \\
& mean & $S D$ & mean & $S D$ & mean & $S D$ \\
\hline $\begin{array}{l}\text { Class 1 } \\
(n=11)\end{array}$ & 11.9 & 4.1 & 13.6 & 2.1 & 13.9 & 2.4 \\
$\begin{array}{l}\text { Class 2 } \\
(n=12)\end{array}$ & 14.0 & 2.0 & 13.9 & 1.4 & 14.2 & 1.8 \\
$\begin{array}{l}\text { Class 3 } \\
(n=11)\end{array}$ & 8.9 & 5.1 & 10.7 & 2.1 & 10.2 & 3.1 \\
$\begin{array}{l}\text { Class 4 } \\
(n=11)\end{array}$ & 14.3 & 1.1 & 13.9 & 2.0 & 14.8 & 0.6 \\
$\begin{array}{l}\text { Class 5 } \\
(n=11)\end{array}$ & 11.7 & 4.7 & 12.7 & 2.0 & 12.6 & 4.6 \\
\hline
\end{tabular}

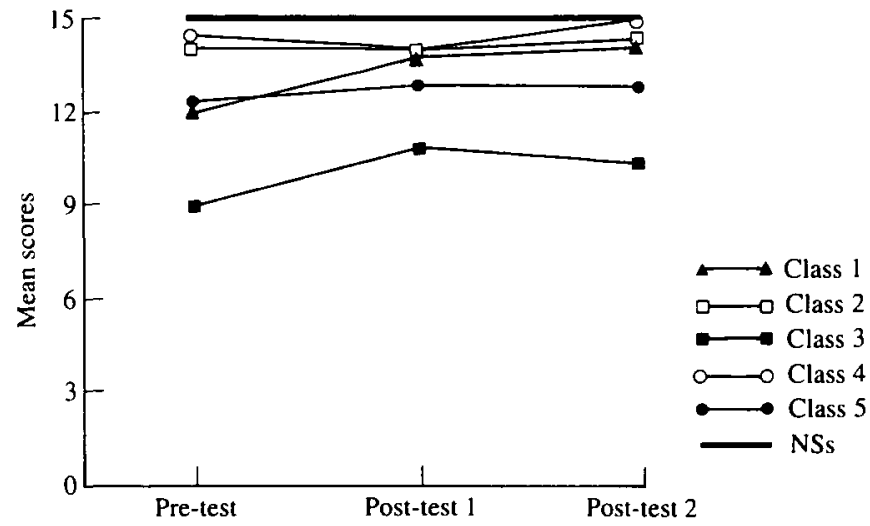

Figure 2: Mean scores on OP informal test

$(1,51)=4.40, p<.05)$, and Class 3 again proved to be different from Classes 1 and $2(F(1,51)=20.05, p<.0001)$. The parameter contrasting Classes 1 and 2 was not significant, and the experimental classes as a group were not significantly different from the comparison classes as a group. There was no treatment effect on the OP informal test since time was not a significant main effect and there was no significant class-by-time interaction.

\subsection{Formal oral production results}

The maximum possible score on the OP formal test was 15 and the mean score attained by the sample of 44 native speakers was $14.6(S D=1.1)$. Class means obtained on three administrations of the OP formal test are displayed in Table 4 and presented graphically in Figure 3 . The univariate analysis indicated that the grouping factor was a significant main effect $(F(4,51)=15.97, p<.0001)$, 
Table 4: Class means on OP formal test

\begin{tabular}{lcccccc}
\hline & \multicolumn{2}{c}{ Pre-test } & \multicolumn{2}{c}{ Immediate post-test } & \multicolumn{2}{c}{ Delayed post-test } \\
& mean & $S D$ & mean & $S D$ & mean & $S D$ \\
\hline $\begin{array}{l}\text { Class 1 } \\
(n=11)\end{array}$ & 4.4 & 4.0 & 12.3 & 3.5 & 11.3 & 3.3 \\
$\begin{array}{l}\text { Class 2 } \\
(n=12)\end{array}$ & 4.7 & 4.1 & 12.3 & 2.3 & 12.1 & 2.8 \\
$\begin{array}{l}\text { Class 3 } \\
(n=11)\end{array}$ & 8.9 & 4.7 & 12.3 & 2.3 & 11.8 & 3.5 \\
$\begin{array}{l}\text { Class 4 } \\
(n=11)\end{array}$ & 2.7 & 1.3 & 3.1 & 1.7 & 3.2 & 1.1 \\
$\begin{array}{l}\text { Class 5 } \\
(n=11)\end{array}$ & 5.0 & 3.6 & 6.2 & 3.9 & 6.4 & 4.1 \\
\hline
\end{tabular}

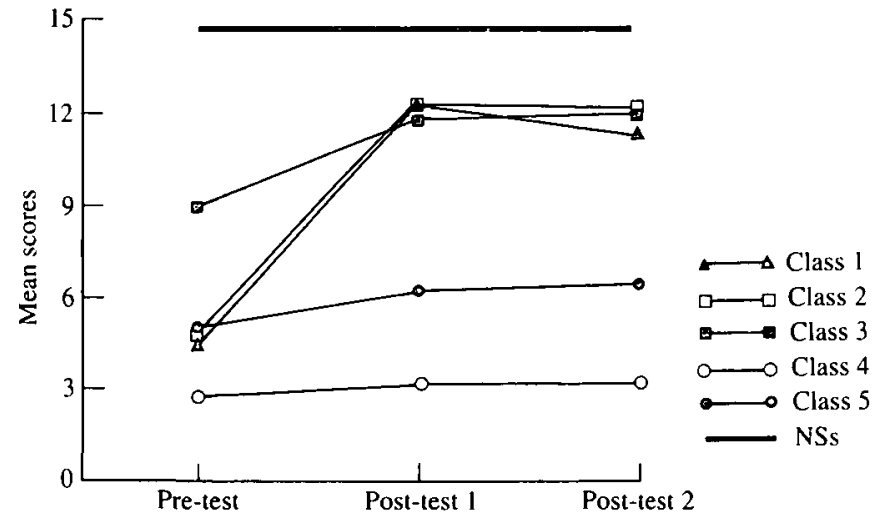

Figure 3: Mean scores on OP formal test

with the experimental classes performing significantly better than the comparison classes $(F(1,51)=55.88, p<.0001)$. To a lesser degree, Class 4 differed significantly from Class $5(F(1,51)=6.08, p<.02)$. The other two contrasts were not significant.

The multivariate analyses revealed the time factor to be a significant main effect $(F(2,50)=42.61, p<.0001)$. There was a significant overall class-bytime interaction $(F(8,100)=5.24, p<.0001)$ whose source was twofold. First, the performance of the experimental classes was significantly different from that of the comparison classes over time $(F(2,50)=16.99, p<.0001)$, the former making considerably more gains than the latter. Second, significant differences distinguished Class 3 from the other two experimental classes over time $(F$ $(2,50)=7.77, p<.01)$, while the other two contrasts were not significant. 
A comparison of the graphs in Figures 2 and 3 reveals a negative correlation between performance on the formal and informal OP measures for at least Classes 3 and 4 . Class 3's lower performance on the informal measure is initially counter to its higher starting point on the formal measure. This reflects the tendency of students in Class 3 to use vous in formal situations more often than other students at the time of pre-testing, and a tendency on the part of some students in Class 3 to also use vous in informal situations throughout the experiment. Conversely, Class 4 attains nearly perfect scores on the informal measure and consistently low scores on the formal, reflecting the tendency of students in this class to use $t u$ in all situations regardless of formality.

\subsection{Multiple choice results}

The maximum number of points attainable on the MC test was 50 , and the mean score achieved by the sample of 80 adolescent native speakers was 44.1 $(S D=5.8)$. Mean scores attained by the five classes on three occasions are presented in Table 5 and depicted graphically in Figure 4. Univariate $F$ tests indicated that the grouping factor was a significant main effect $(F(4,93)=11.12, p<.0001)$. Experimental classes were significantly different from comparison classes $(F(1,93)=37.79, p<.0001)$, achieving higher results on the grand mean, and to a lesser degree, the two comparison classes were significantly different from one another $(F(1,93)=6.11, p<.02)$. The other two contrasts were not significant.

Multivariate analyses revealed a significant time effect $(F(2,92)=76.85$, $p<.0001)$ and a significant class-by-time interaction $(F(8,184)=8.80$, $p<.0001)$. The source of this significant interaction was due solely to large differences manifested over time between the experimental group and the comparison group $(F(2,92)=37.08, p<.0001)$.

Table 5: Class means on MC test

\begin{tabular}{lllllll}
\hline & \multicolumn{2}{c}{ Pre-test } & \multicolumn{2}{c}{ Immediate post-test } & \multicolumn{2}{c}{ Delayed post-test } \\
& mean & $S D$ & mean & $S D$ & mean & $S D$ \\
\hline $\begin{array}{l}\text { Class 1 } \\
(n=26)\end{array}$ & 20.5 & 4.4 & 35.0 & 7.7 & 35.7 & 7.0 \\
$\begin{array}{l}\text { Class 2 } \\
(n=21)\end{array}$ & 22.9 & 8.4 & 35.3 & 6.1 & 33.8 & 4.9 \\
$\begin{array}{l}\text { Class 3 } \\
(n=15)\end{array}$ & 24.1 & 6.7 & 36.1 & 7.5 & 35.1 & 6.9 \\
$\begin{array}{l}\text { Class 4 } \\
(n=21)\end{array}$ & 21.1 & 7.5 & 21.4 & 6.2 & 22.1 & 7.0 \\
$\begin{array}{l}\text { Class 5 } \\
(n=15)\end{array}$ & 26.1 & 6.1 & 25.2 & 9.3 & 27.6 & 7.9 \\
\hline
\end{tabular}




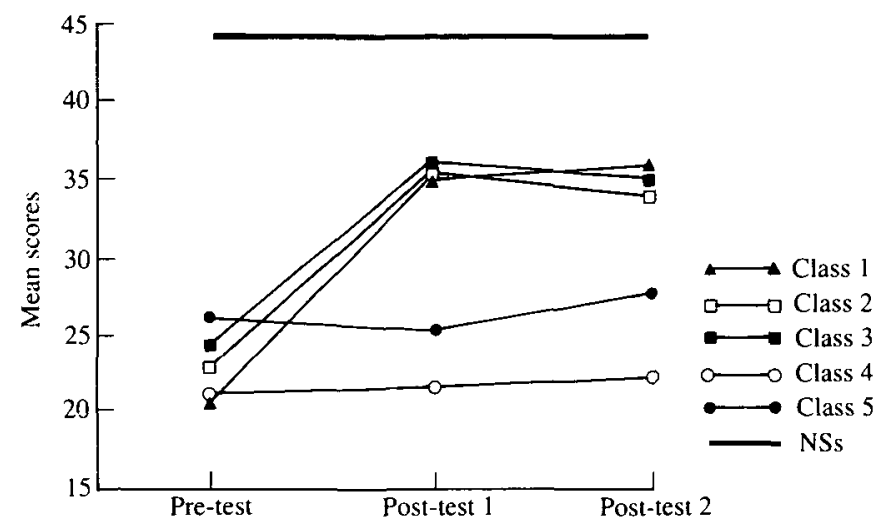

Figure 4: Mean scores on MC test

\section{SUMMARY}

Test results in this study clearly indicate that over time (approximately seven weeks between pre-tests and immediate post-tests, and four weeks between immediate and delayed post-tests) ${ }^{8}$ experimental classes as a group performed significantly differently from comparison classes on sociolinguistic measures of written production, formal oral production, and multiple choice. In written production, Classes 1 and 2 made considerable progress from pre-test to immediate post-test, and maintained this higher level of achievement at the time of delayed post-testing, thus matching Class 3's initially high starting point which was maintained over time. Similarly, in formal oral production and on the multiple-choice test, the three experimental classes made significant progress over time relative to comparison classes, achieving similarly high scores on immediate post-tests and maintaining this level of achievement at the time of delayed post-testing.

In written production, progress made by the experimental group was due primarily to the improved use of vous in the formal letters produced by students in Classes 1 and 2 . To a lesser degree, gains in written production were initially made by Classes 1 and 2 in the use of polite closings in formal letters, but were not maintained at a significant level at the time of delayed post-testing. In their use of questions and/or politeness expressions, immersion students did not perform differently from native speakers at the time of pre-testing, and so experimental and comparison classes invariably made no significant gains in this category as they maintained their native-like use over time. With respect to conditionals, neither experimental nor comparison classes made gains over time, consistently using fewer conditionals in formal letters than did native speakers of the same age.

Measures of oral production were evaluated solely in accordance with accurate and appropriate use of $t u$ and vous. Multivariate $F$ tests revealed no 
treatment effect in the informal situations, since generally high pre-test scores precluded significant growth over time in most classes, indicating that immersion students for the most part had few difficulties in using $t u$ in informal situations. However, univariate $F$ tests revealed that Class 3 performed significantly differently from Classes 1 and 2, its lower scores indicating that some students in Class 3 continued to use vous in informal situations throughout the experiment. In the formal situations, the experimental classes' significant growth over time revealed their increased use of vous in formal contexts.

Significant gains made by experimental classes on the MC test revealed substantial improvement in the ability to recognize contextually appropriate language. It is interesting to note, however, that the experimental classes' mean scores invariably leveled off around 35 on this test scored out of a possible 50 points, faliing short of the native-speaker norm of 44.1 determined by francophone students of the same age.

Thus, the quantitative results indicate that functional-analytic teaching improved the sociolinguistic competence of Grade 8 FI students in at least three ways:

1. by significantly increasing their ability in oral production to appropriately and accurately use vous in formal situations;

2 . by significantly increasing their ability in written production to appropriately use vous in formal letters, and, in the short run, to use polite closings in formal letters; and

3. by significantly increasing their awareness of socio-stylistic differences in the L2, including their ability to recognize contexts as being appropriate for specific utterances, and to recognize utterances as being appropriate for given contexts.

\section{DISCUSSION}

In terms of the analytic-experiential option, analytic strategies predominated throughout this investigation, emphasizing accuracy and appropriateness in the study and practice of speech acts and sociolinguistic features, while experiential strategies emerged in a supporting role as a result of the experiential context provided by FI classrooms. According to classroom observations and student questionnaire data, Teacher 1 proved to be the most receptive to functionalanalytic teaching. He tended to provide cognitively engaging feedback which pushed students to be more precise in their choice of words, to produce more appropriate utterances, and to reflect on their performance through subsequent analysis and discussion. He also asked questions which built on students' previous responses, thereby pushing students to explain and further develop their knowledge of sociolinguistic features. Furthermore, he succeeded in integrating analytic teaching with experiential strategies by fostering an interplay between communication and reflection on that communication through discussions on language use and group activities with an analytic focus. These analytic strategies are described in more detail as the 'negotiation of form' in Lyster (1994a). 
With respect to the explicit-implicit option in L2 teaching, an interesting finding emerged in the data. The explicit emphasis on the tulvous distinction which was maintained throughout the experimental treatment resulted in substantial improvement in the appropriate use of vous in written and oral production. The use of the conditional, however, which was presented more implicitly throughout the treatment as an incidental marker of politeness, did not increase in formal contexts either in written or oral production. Regarding the use of polite closings in formal letters, the greatest gains were made by Class 2 where the teacher spent at least two lessons on formal letter writing and provided three samples of formal letters in addition to the one included in the materials. The significant gains, however, were not maintained one month later. These findings suggest that improvement is more likely in the case of explicit attention, and that such improvement is more easily maintained in the case of structurally simple elements such as vous, and more difficult to maintain in the case of grammatically complex phrases used in polite closings.

In terms of learning theory, results of the present study suggest that 'learning' may lead to 'acquisition' more readily than predicted by the Monitor Model (Krashen 1982, 1985), and that ostensibly fossilized forms in the immersion interlanguage (cf. Lyster 1987) may develop into more appropriate forms through a restructuring of internal representations of knowledge, as predicted by the information-processing model of L2 learning (McLaughlin 1987, 1990). The restructuring may be activated by controlled processes involving activities which first promote the perception of language functions and their appropriate forms in various contexts, followed by their use in written and oral production activities including student interaction and role plays. The findings indicate that classroom intervention involving such activities may allow students to learn socially appropriate forms to an extent not equalled by the limited exposure to socio-stylistic variation generally provided by the immersion context.

Although this study indicates that instruction focusing on the use of $t u$ and vous in immersion classrooms is more effective than no such instruction, no clear claims can be put forth concerning the effectiveness of this type of instruction relative to other types of instruction. However, it may be argued that a more traditional approach, involving rule formulation and repetition (cf. Hammerly 1989), would not be equally effective in that such instruction does not lend itself well to the fluid nature of socio-stylistic variation. That is, the functionalanalytic treatment in this experiment did not aim to prescribe rules, but rather to develop the learners' ability to make informed choices with respect to sociostylistic variation. Consequently, many of the activities remained open-ended to a certain extent. Recognition exercises requiring the classification of utterances as neutral, formal, or informal, allowed for disagreement among students who in turn were expected to justify their positions. Similarly, production activities, including role plays, were designed to allow students to make personal choices pertaining to socio-stylistic variation in accordance with their perception of (1) the context of the interaction and its purpose, and (2) the personal characteristics of the participants and their relationship. 
While the overall instructional approach was effective in this study, it remains difficult to determine which aspects of the instruction contributed to the learning. Was the students' improvement in their use of vous due to the activities providing contextualized examples which were analyzed in terms of rules of socio-stylistic variation, and/or did the subsequent production activities contribute to the success? Although this experiment was not designed in such a way as to tease apart the roles of comprehension and production, it seems reasonable to expect that the activities promoting recognition of socio-stylistic differences may have been adequate to ensure success on the multiple-choice test, but that written and oral production activities promoting the sustained and appropriate use of $t u$ and vous contributed to the learners' successful results on the written and oral production tests. In the immersion context at the Grade 8 level, learners have been using the L2 communicatively for years, although not always accurately. As a result, they may need to unlearn the use of certain language features, such as the overuse of $t u$ in formal contexts. Harley (1989:355) points out that immersion students 'appear to develop strategies that are useful and sufficient for classroom communication, and that may become progressively more difficult to overcome (for example, overusing the present tense to refer to the past)'. Consequently, it may be the case that a restructuring of knowledge representations, allowing for the development of new automatized routines involving more appropriate forms, is supported by language production at the level of controlled processing, and not by recognition activities alone. As McLaughlin (1987: 134) maintains, once learned, 'an automatic process occurs rapidly and is difficult to suppress or alter', thus providing an explanation for what appear to be fossilized forms in the FI interlanguage. In the present study, the automatized routines which most FI students demonstrated in their extensive use of $t u$ at the time of pre-testing remained difficult for some students to suppress at the time of post-testing, thereby contributing to the gap in achievement levels between experimental classes and native speakers.

The gap between experimental classes and native speakers may also be due to a ceiling effect experienced by experimental classes at the time of post-testing, since their post-test scores in written production and formal oral production were equivalent in spite of variable pre-test scores. Such a ceiling effect may be an inevitable result of classroom instruction. That is, it may be the case that sociolinguistic features, given the intrinsically social nature of sociolinguistic competence, can be successfully taught in classroom settings only to a limited extent. Thus, the limitations of the classroom context, which restrict, for example, the authentic use of the social function of vous (described by Swain and Carroll 1987), are perhaps bound to persist in classrooms in spite of explicit instruction. Experience in an authentic target language milieu may be necessary to ensure further improvement. Consequently, the intervention in this study did not allow experimental students to achieve performance levels identical to those of native speakers on measures of written production, formal oral production, or multiple choice. ${ }^{9}$

Notwithstanding such differences between experimental classes and native 
speakers, the differences in performance which developed over time between experimental and comparison classes are indeed striking, more so than differences detected in the Harley (1989) and Day and Shapson (1991) studies. There may be at least four reasons for this relative success.

First, it is important to point out that due to time restrictions imposed on the design of the present study, delayed post-testing occurred only one month after the treatment, compared to a three-month delay in the Harley (1989) and Day and Shapson (1991) studies.

Second, as mentioned earlier, the present study was conducted at a higher grade level than the other two studies. Consequently, a stronger analytic focus was included in the treatment materials, which served to consistently remind students of the sociolinguistic focus through activities involving more guided practice in oral expression than was evident in the previous experiments. At the conclusion of her study, Harley indicated that the treatment materials promoted more focus on content than on form (even for teachers), and furthermore, that many students had not mastered the formal aspects of the verb inflections. In both previous studies, the functional-analytic focus of some activities may have proven to be primarily experiential, in that the analytic focus on verbs, particularly in oral activities, was superseded by more spontaneous expression and the concomitant use of simplified forms. For example, Day and Shapson noted in their study a tendency in the speaking tasks for students to contextualize their speech in the present, thus eliminating the need to use the conditional to express hypothetical meaning.

Third, based on follow-up questionnaire data, the two previous studies indicated that some comparison classes were also focusing on the grammar features in question, resulting in growth over time on some measures for comparison classes, thereby reducing differences between experimental and comparison groups. In the present study, observations in comparison classes and interviews with comparison teachers clearly indicated that no attention was drawn to sociolinguistic features in these classes. It appears that when immersion teachers do provide an analytic focus, grammatical features are targeted rather than sociolinguistic features. For example, during the treatment in experimental classes, comparison Class 5 devoted considerable time to a thematic unit involving the creation of a board game. In groups, students devised a game which was to be presented to the class. The class presentation included an advertisement for the game as well as a detailed explanation of the rules. Teacher 5 indicated that the linguistic objective of the unit was to have students practise using imperative verb forms. This was a linguistic focus which was indeed related to the content of the treatment materials. However, when asked whether the use of $t u$ or vous had been encouraged, Teacher 5 could not recall which forms the textbook had used, and in the final products which he had already evaluated, the mixture of $t u$ and vous forms which abounded in the students' writing had received no feedback.

Fourth, the passé composélimparfait distinction and the conditional mood are structurally and semantically more complex than the tu/vous distinction. That 
the tu/vous distinction is linguistically simpler probably renders it more amenable to improvement as a result of instruction. As Schwartz (1993) claims, the provision of explicit data to $\mathrm{L} 2$ learners might be most effective in regard to the lexicon. Viewed as deriving from the lexicon rather than from syntax, the $t w$ vous distinction may thus lend itself well to explicit attention. The complexity of the tu/vous distinction lies not in its grammatical formulation, then, but rather in the speaker's need to assess various aspects of the social context. This task is rendered more difficult for the $\mathrm{L} 2$ learner whose $\mathrm{L} 1$ is English since there is no equivalent distinction in English pronominal reference. Consequently, the $t w$ vous distinction may be a feature which is not only amenable to improvement through instruction, but may indeed require some instruction. Since the notion of socio-stylistic variation is of course not new to native speakers of English, there may be a general transfer of sociolinguistic awareness. However, appropriate performance will depend on the learner's declarative and procedural knowledge pertaining to L2 forms and their use. In the case of tu/vous usage, negative transfer may persist in the limited social context of immersion classrooms where students seem to have deduced that $t u$ equals you and consequently consider vous as redundant in singular contexts (and even in some plural contexts). Use of this reduction strategy was significantly altered in the present study as a result of classroom intervention using a functional-analytic approach. Learning the social functions underlying the formal/informal dichotomy in French second-person pronominal reference, notwithstanding the absence of similar distinctions in English pronominal reference and the potentially difficult task of assessing social variables, would appear to be a simpler task than the learning of aspectual and modal distinctions in the French verb system. As Schmidt (1993) suggests, pragmatic features of a language may be particularly amenable to conscious learning, thus providing a further explanation for the notable improvement in experimental students' use of vous in this classroom experiment.

To conclude with reference to future research of this kind, it is recommended that researchers and teachers collaborate to further develop effective analytic teaching strategies such as the negotiation of form techniques discerned in Class 1. Cooperative learning activities with an analytic focus could also be further explored, since this type of activity in the present study generated an exemplary integration of analytic and experiential strategies.

(Revised version received December 1993)

\section{ACKNOWLEDGEMENTS}

I would like to thank Birgit Harley, Patsy Lightbown, and Nina Spada for their helpful comments on earlier versions of this paper, as well as the Applied Linguistics editors and anonymous reviewers for their insightful suggestions. I am also grateful to the Ontario Educational Research Council for providing partial funding to complete the statistical analyses. 


\section{NOTES}

1 For further discussion of the analytic-experiential dimension in immersion contexts, see also Harley (1993), Rebuffot (1993), and Lyster (1990).

2 This teacher gave his assurances that he would not replicate any of the experimental activities in his comparison class. While this may have been difficult for many teachers, he pointed out that he rarely did the same activities in both classes because he liked variety in his teaching. Subsequent observations in both his classes (six and a half hours in Class 2 and four hours in Class 4) confirmed this. While it could be argued that Teacher 2 may have intentionally neglected to focus on sociolinguistic features which could have naturally arisen in Class 4 , it was clear from the classroom observations as well as from the investigator's prior experience in immersion classrooms, that teachers tend not to focus on sociolinguistic features unless they have access to materials which explicitly do so, such as the ones used in this study.

3 Three points were awarded for the consistent use of $t u$ in the five informal situations, and for the consistent use of vous in the five formal situations. Two points were awarded for the consistent use of $t u$ in three formal situations: asking the teacher for help in math, asking the librarian for his ruler, and asking the adult to stop pushing. When $t u$ and vous forms were used consistently but were mixed with non-corresponding verb forms (including the imperative), then only one point was awarded. No points were awarded for the use of $t u$ and vous forms together in the same situation, unless the subject self-corrected. No points were awarded for the use of vous in informal situations, or for the use of $t u$ in formal situations other than the three aforementioned exceptions.

4 A frequency count of conditionals was conducted on utterances elicited in oral production in order to determine whether the analysis of OP measures should be expanded to include the use of conditionals in addition to the use of $t u$ and vous. Included in the frequency count were conditionals produced in the formal situation in which students were to ask an unknown adult for directions, since this situation had elicited the most frequent use of conditionals by native speakers: 66 per cent of the sample of 44 adolescent native speakers used at least one conditional. The frequency count was conducted on the immersion data using the pre-test and two post-tests for each of the twelve students in each class, resulting in 36 occurrences for each class. Of the 36 occurrences, four from Class 1 contained a conditional, two from Class 2, one from each of Classes 3 and 4 , and none from Class 5 . It was decided that the small number of conditionals produced by FI students in oral production did not warrant further analysis.

${ }^{5}$ Swain (1988b: 16) has argued that low measures of internal consistency are to be expected on sociolinguistic tests designed to assess language variation. She suggests that 'a]n internally consistent test of sociolinguistic behaviour-given our present knowledge-would be difficult to devise, and most importantly, it would not be reflective of language use in complex and diverse social situations'. This was further corroborated by our analysis of the OP test. Based on pre-test results, an item analysis of each form of the $O P$ test as a unified measure consisting of ten situations did not reveal good test reliability $($ alpha $=.08$ for Form A and .39 for Form B). When each form was divided into a formal test and an informal test, considerably better reliabilities were obtained: on the formal test, alpha $=.86$ for Form A and .74 for Form B; on the informal test, alpha $=.79$ for Forms $A$ and $B$. This is why the OP measure was analyzed as two separate tests: formal OP and informal OP. An item analysis was also conducted on each form of the WP test, based on pre-test scores of 105 FI students, using the difference scores for each of the four categories as 'items', although the WP test did not truly consist of items per se (and 
the difference scores did not allow for separate analyses of formal and informal measures). Not surprisingly, test reliabilities were low: on Form $\mathrm{A}$, alpha $=.28$; on Form $\mathrm{B}$, alpha $=.22$. Low test reliabilities had also been obtained on the WP test in Harley, Allen, Cummins, and Swain (1987, 1990).

6 The repeated measures design generates trend analyses which include analysis of the linear trend resulting from differences between pre-test scores and delayed post-test scores, and analysis of the quadratic trend which is determined by comparing immediate post-test scores to delayed post-test scores on the one hand, and to pre-test scores on the other. The significance levels of the linear and quadratic trends are reported in Lyster (1993).

7 This simpler analysis is undertaken by the Wilcoxon Matched-Pairs Signed-Ranks test, a non-parametric test which compares two related samples by analyzing the data on an ordinal scale. Such an analysis was made necessary by the small distribution of scores for each WP formal feature, all of which include a range of only three possible scores. Thus, the assumptions for a repeated measures analysis of variance were not met, and furthermore, a subdivision of the repeated measures MANOVA into further multiple comparisons would have weakened the statistical design.

8 Although the treatment materials were implemented for an average period of five weeks, there was a seven-week interval between pre-tests and immediate post-tests, due to a one week vacation period and long testing sessions.

" In addition to the potential ceiling effect, it may also be the case that Class 3's initially high results on some measures reflected a familiarity with the material which resulted in a lower level of interest than that of the other experimental classes, which in turn hindered more significant improvement over time for students in Class 3. Such familiarity seemed to derive from previous explicit instruction regarding the use of vous, resulting in a more extensive use of vous in formal letters and formal oral situations at the time of pre-testing relative to other classes, but also a comparatively greater use of vous in informal notes and informal oral situations. This type of error, which may be attributable to overuse resulting from previous instruction, was detected mainly among students in Class 3 and was not altered as a result of the experimental treatment.

\section{REFERENCES}

Allen, P. 1983. 'A three-level curriculum model for second-language education.' The Canadian Modern Language Review 40/1: 23-43.

Allen, P., M. Swain, B. Harley, and J. Cummins. 1990. 'Aspects of classroom treatment: Toward a more comprehensive view of second language education' in Harley, Allen, Cummins, and Swain 1990: 57-81.

Brumfit, C. 1984. Communicative Methodology in Language Teaching: The Roles of Fluency and Accuracy. Cambridge: Cambridge University Press.

Canale, M. 1983. 'From communicative competence to language pedagogy' in J. Richards and J. Schmidt (eds.) 1983: Language and Communication. London: Longman.

Canale, M. and M. Swain. 1980. 'Theoretical bases of communicative approaches to second language teaching and testing.' Applied Linguistics 1/1: 1-47.

Day, E. and S. Shapson. 1991. 'Integrating formal and functional approaches to language teaching in French immersion: An experimental study.' Language Learning 41/1: 2558.

Finocchiaro, M. and C. Brumfit. 1983. The Functional-Notional Approach: From Theory to Practice. Oxford: Oxford University Press. 
Genesee, F. 1987. Learning Through Two Languages: Studies of Immersion and Bilingual Education. Cambridge, MA: Newbury House.

Hammerly, H. 1989. French Immersion: Myths and Reality. Calgary: Detselig Enterprises Ltd.

Harley, B. 1989. 'Functional grammar in French immersion: A classroom experiment.' Applied Linguistics 10/3: 331-59.

Harley, B. 1993. 'Instructional strategies and SLA in early French immersion.' Studies in Second Language Acquisition 15/2:245-60.

Harley, B. and M. Swain. 1984. 'The interlanguage of immersion students and its implications for second language teaching' in A. Davies, C. Criper, and A. Howatt (eds.) 1984: Interlanguage. Edinburgh: Edinburgh University Press.

Harley, B., P. Allen, J. Cummins, and M. Swain. 1987. Development of Bilingual Proficiency, Final Report. Volume II: Classroom Treatment. Toronto: Modern Language Centre, The Ontario Institute for Studies in Education.

Harley, B., P. Allen, J. Cummins, and M. Swain. 1990. The Development of Second Language Proficiency. Cambridge: Cambridge University Press.

Harley, B., J. Cummins, M. Swain, and P. Allen. 1990. 'The nature of language proficiency' in Harley, Allen, Cummins, and Swain 1990.

Hulstijn, J. 1990. 'A comparison between the information-processing and the analysis/ control approaches to language learning.' Applied Linguistics 11/1:30-45.

Krashen, S. 1982. Principles and Practice in Second Language Acquisition. New York: Pergamon Press.

Krashen, S. 1985. The Input Hypothesis: Issues and Implications. London: Longman.

Lambert, W. E. and G. R. Tucker. 1972. Bilingual Education of Children: The St. Lambert Experiment. Rowley, MA: Newbury House.

Lightbown, P. and N. Spada. 1990. 'Focus-on-form and corrective feedback in communicative language teaching: Effects on second language learning.' Studies in Second Language Acquisition 12/4: 429-48.

Long, M. 1991. 'Focus on form: A design feature in language teaching methodology' in K. de Bot, R. Ginsberg, and C. Kramsch (eds.) 1991: Foreign Language Research in CrossCultural Perspective. Amsterdam/Philadelphia: John Benjamins.

Lyster, R. 1987. 'Speaking immersion.' The Canadian Modern Language Review 43/4: $701-17$.

Lyster, R. 1990. 'The role of analytic language teaching in French immersion programs.' The Canadian Modern Language Review 47/1: 159-76.

Lyster, R. 1993. The Effect of Functional-Analytic Teaching on Aspects of Sociolinguistic Competence: A Study in French Immersion Classrooms at the Grade 8 Level. PhD dissertation. University of Toronto.

Lyster, R. 1994a. 'La négociation de la forme: Stratégie analytique en classe d'immersion.' The Canadian Modern Language Review 50/3: 446-65.

Lyster, R. 1994b. Variation en situation de communication: unité sur les niveaux de langue en français. Montreal: Department of Education in Second Languages, McGill University.

McLaughlin, B. 1987. Theories of Second-Language Learning. London: Edward Arnold.

McLaughlin, B. 1990. 'Restructuring.' Applied Linguistics 11/2: 113-28.

O'Malley, M., A. Chamot, and C. Walker. 1987. 'Some applications of cognitive theory to second language acquisition.' Studies in Second Language Acquisition 9/3: 287306. 
Rebuffot, J. 1993. Le point sur l'immersion au Canada. Montreal: Centre Educatif et Culturel.

Rutherford, W. 1987. Second Language Grammar: Learning and Teaching. London: Longman.

Schmidt, R. 1993. 'Consciousness, learning, and interlanguage pragmatics' in G. Kasper and S. Blum-Kulka (eds.) 1993:Interlanguage Pragmatics. New York: Oxford University Press.

Schwartz, B. 1993. 'On explicit and negative data effecting and affecting competence and linguistic behaviour.' Studies in Second Language Acquisition 15/2: 147-64.

Sharwood Smith, M. 1993. 'Input enhancement in instructed SLA: Theoretical bases.' Studies in Second Language Acquisition 15/2: 165-80.

Spada, N. and P. Lightbown. 1993. 'Instruction and the development of questions in L2 classrooms.' Studies in Second Language Acquisition 15/2: 205-24.

Stern, H. H. 1990. 'Analysis and experience as variables in second language pedagogy' in Harley, Allen, Cummins, and Swain 1990.

Stern, H. H. 1992. Issues and Options in Language Teaching. Oxford: Oxford University Press.

Swain, M. 1988a, 'Manipulating and complementing content teaching to maximize second language learning.' TESL Canada Journal 6/1: 68-83.

Swain, M. 1988b. 'Language measurement at the crossroads.' Plenary paper presented at the 11 th Annual Conference of the American Association of Applied Linguistics. New Orleans.

Swain, M. and S. Carroll. 1987. 'The immersion observation study' in Harley et al. 1987.

Swain, M. and S. Lapkin. 1982. Evaluating Bilingual Education: A Canadian Case Study. Clevedon, Avon: Multilingual Matters.

Swain, M. and S. Lapkin. 1990. 'Aspects of the sociolinguistic performance of early and late French immersion students' in R. Scarcella, E. Andersen, and S. Krashen (eds.) 1990: Developing Communicative Competence in a Second Language. New York: Newbury House Publishers.

White, L. 1991. 'Adverb placement in second language acquisition: Some effects of positive and negative evidence in the classroom.' Second Language Research 7: 133-61.

Widdowson, H. G. 1990. Aspects of Language Teaching. Oxford: Oxford University Press.

Yalden, J. 1987. Principles of Course Design for Language Teaching. Cambridge: Cambridge University Press. 